\title{
BMJ Open Compliance with ethical standards in the reporting of donor sources and ethics review in peer-reviewed publications involving organ transplantation in China: a scoping review
}

\author{
Wendy Rogers, ${ }^{1,2}$ Matthew P Robertson, ${ }^{3}$ Angela Ballantyne, ${ }^{4}$ Brette Blakely, ${ }^{5}$ \\ Ruby Catsanos, ${ }^{6}$ Robyn Clay-Williams, ${ }^{7}$ Maria Fiatarone Singh ${ }^{8}$
}

To cite: Rogers W,

Robertson MP, Ballantyne A, et al. Compliance with ethical standards in the reporting of donor sources and ethics review in peer-reviewed publications involving organ transplantation in China: a scoping review. BMJ Open 2019;9:e024473. doi:10.1136/ bmjopen-2018-024473

- Prepublication history and additional material for this paper are available online. To view these files, please visit the journal online (http://dx.doi org/10.1136/bmjopen-2018024473).

Received 30 May 2018 Revised 28 September 2018 Accepted 13 November 2018

Check for updates

(C) Author(s) (or their employer(s)) 2019. Re-use permitted under CC BY-NC. No commercial re-use. See rights and permissions. Published by BMJ.

For numbered affiliations see end of article.

Correspondence to Professor Wendy Rogers; wendy.rogers@mq.edu.au

\section{ABSTRACT}

Objectives The objective of this study is to investigate whether papers reporting research on Chinese transplant recipients comply with international professional standards aimed at excluding publication of research that: (1) involves any biological material from executed prisoners; (2) lacks Institutional Review Board (IRB) approval and (3) lacks consent of donors.

Design Scoping review based on Arksey and 0'Mallee's methodological framework.

Data sources Medline, Scopus and Embase were searched from January 2000 to April 2017.

Eligibility criteria We included research papers published in peer-reviewed English-language journals reporting on outcomes of research involving recipients of transplanted hearts, livers or lungs in mainland China.

Data extraction and synthesis Data were extracted by individual authors working independently following training and benchmarking. Descriptive statistics were compiled using Excel.

Results 445 included studies reported on outcomes of 85477 transplants. 412 (92.5\%) failed to report whether or not organs were sourced from executed prisoners; and $439(99 \%)$ failed to report that organ sources gave consent for transplantation. In contrast, 324 (73\%) reported approval from an IRB. Of the papers claiming that no prisoners' organs were involved in the transplants, 19 of them involved 2688 transplants that took place prior to 2010 , when there was no volunteer donor programme in China.

Discussion The transplant research community has failed to implement ethical standards banning publication of research using material from executed prisoners. As a result, a large body of unethical research now exists, raising issues of complicity and moral hazard to the extent that the transplant community uses and benefits from the results of this research. We call for retraction of this literature pending investigation of individual papers.

\section{INTRODUCTION}

The transplantation of organs procured from executed prisoners is widely condemned
Strengths and limitations of this study

- The main strengths of this study lie in its originality and in the use of robust scoping review methods, giving confidence that the results are reliable.

- The study provides evidence that a large number of published papers violate ethical standards by including data on transplants involving organs procured from prisoners.

- The data set was limited by exclusion of publications in languages other than English, or published in Chinese journals, regardless of the language of publication.

- The data in the included studies were imprecise regarding organ sources.

- The total number of participants (and hence number of transplants) in the included studies is inflated by multiple publication of the same and overlapping research cohorts.

by bodies including WHO, ${ }^{1}$ the World Medical Association, ${ }^{2}$ The Transplantation Society (TTS), ${ }^{3}$ Amnesty International and the Declaration of Istanbul. ${ }^{45}$ This condemnation extends to undertaking research and presenting results that involve the use of organs obtained from executed prisoners. ${ }^{4}$ In 2006, TTS explicitly stated that it would not accept conference papers based on research involving organs sourced from executed prisoners. ${ }^{6} 7$ The 2006 policy statement by TTS was followed by calls for a boycott on accepting conference papers or publishing journal articles based on research involving organs from executed prisoners. ${ }^{8-10}$ Some journals explicitly adopted this ban as policy (Journal of Clinical Investigation, ${ }^{11}$ American Journal of Transplantation and the Journal of Heart and Lung Transplantation). ${ }^{9}$ 
Together, these statements by international bodies, professional societies, academics and journals constitute explicit ethical standards prohibiting the publication or presentation of research involving organs sourced from executed prisoners. These standards are primarily directed towards peer-reviewers, editors and publishers. However, these standards lack regulatory force; there are no sanctions for breaches, and to date there has been no audit investigating compliance.

This study is the first attempt to track the progress of the transplant community in meeting this ethical injunction to avoid publication of research based on organs sourced from executed prisoners.

\section{BACKGROUND}

The prohibition against the use of executed prisoners' organs is explicitly directed towards China, which is one of the few countries where the use of prisoners' organs has been government-sanctioned. In 2001, a Chinese official dismissed as 'sensational lies' reports of organ harvesting from executed prisoners, claiming that the major source of organs was voluntary donations. ${ }^{12}$ This rhetoric changed in 2006 when Chinese officials first openly acknowledged that the majority of transplanted organs were sourced from executed prisoners. ${ }^{13}{ }^{14} \mathrm{In}$ 2007, China claimed it would reduce reliance on executed prisoners ${ }^{15}$ but in a 2015 interview, Huang Jiefu, China's most senior transplant official, stated that there had been just 120 cases of volunteer donors up to $2009 .^{16}$ In 2014, Huang committed China to using only organs from volunteer donors from 1 January 2015. ${ }^{17}$ However, the use of prisoners' organs remains technically legal today in China if 'consent' is obtained, ${ }^{18}$ and in 2017 Chinese officials admitted that it is not possible to verify that all organ harvesting from prisoners has ceased. ${ }^{19}$

Use of organs from executed prisoners is widely condemned because the coercive situation of being on death row undermines the possibility of ethically valid consent, or consent may not be sought at all. ${ }^{20}$ In addition, in China there have been extensive and credible reports of non-voluntary organ harvesting from prisoners of conscience, adding to ethical concern. ${ }^{2122}$

The transplant community recognises that boycott is an effective way to express condemnation of Chinese organ procurement practices, leading to formal TTS policy and recommendations for banning unethical research as described above. Publication in international, peer-reviewed journals is a marker of academic success and international acceptance. Imposing a ban sends a strong message of disapprobation to researchers whose projects involve transplants of organs sourced from executed prisoners.

The current approach to this issue taken by TTS and some journals is incremental rather than absolutist. ${ }^{10}$ An 'absolutist' approach would ban publication of all Chinese transplant data until there is compelling positive evidence that the use of executed prisoners' organs has ceased. This would require free and full on-site inspections of Chinese transplant hospitals, including unfettered access to hospital information systems. China has not agreed to such inspections and no international or professional body has assumed responsibility for pursuing this issue. Instead, the professions' preferred incremental approach requires assessment of Chinese studies for ethical acceptability prior to publication, with exclusion of any that include data from executed prisoners. The incremental policy therefore requires peer-reviewers and journal editors to ask consistently whether the research: (1) involved any biological material sourced from executed prisoners; (2) received Institutional Review Board (IRB) (Research Ethics Committee) approval and (3) required consent of donors. For transparency purposes, this information should be included in the final publication. Transparency contributes to a culture of accountability and ensures that readers are not unwittingly absorbing and using unethically obtained data. The burden of proof should rest with authors/researchers to supply evidence of consent to donation, and approval by an IRB, and attest that their study does not use material derived from executed prisoners.

In this study, we investigated the extent to which journals have complied with these ethical standards by: (1) publishing only research using organs from volunteer donors; (2) requiring a statement of IRB approval and (3) providing a statement that consent was obtained from donors. As noted above, 'consent' obtained from executed prisoners does not meet international ethical standards.

\section{METHODS}

This research used scoping review methodology. Scoping reviews can be used to map an area of research, summarise existing evidence or identify gaps in the literature. Unlike systematic reviews, scoping reviews usually do not assess the quality of the included studies. ${ }^{23}$ This review followed the five steps articulated by Arksey and O'Mallee to ensure rigour, transparency and facilitate replication (table 1). ${ }^{24}$

The research question was identified and refined through discussion among the authors and expert colleagues. The final version was: 'To what extent do papers reporting research on Chinese transplant recipients: identify the sources of organs; state whether sources

Table 1 Arksey and O'Mallee's methodological framework for a scoping review

\begin{tabular}{ll}
\hline Framework stage & Description \\
\hline 1 & Identifying the research question \\
2 & Identifying relevant studies \\
3 & Study selection \\
5 & $\begin{array}{l}\text { Charting the data } \\
\text { Collating, summarising and reporting } \\
\text { the results }\end{array}$ \\
\hline
\end{tabular}




\section{Box 1 Exclusion criteria for full-text review of papers}

- 'Animal research'-exclude any non-human research.

- 'Chinese journal'-exclude any papers published in (English language) journals published in China, on the assumption of low compliance with Western ethical standards.

- 'Case report'-exclude papers reporting on clinical case reports.

- 'Incidental inclusion' - exclude papers where transplant recipients are incidentally included as research participants.

- 'Kidneys' - exclude any papers reporting data from kidney transplant recipients due to ambiguity of source (living or deceased).

- 'Living donors'-exclude papers where all the transplanted organs were procured from living donors, including split livers from living donors.

- 'Not China'-exclude any papers where the transplants took place outside mainland China.

- 'Not reviewed'-exclude any non-peer-reviewed publications (including commentaries, letter to editors, etc).

- 'Other organs'-exclude other tissue or organs, that is, not livers, hearts or lungs.

- 'Other'-state reason.

- 'Review paper' - exclude review papers (meta-analysis, systematic reviews, etc).

were living or deceased; and comply with ethical requirements for human research and organ donation as per international guidelines and professional standards?'

\section{Search strategy}

Relevant studies in English-language journals were identified through searching online databases. The electronic search strategies were developed, tested and refined with the assistance of an expert librarian. The search aimed to identify full-text papers published in English in peer-reviewed journals by authors based at Chinese institutions that reported on research involving recipients of solid organ transplants. The search strategies for Medline, Scopus and Embase are described in online supplementary file 1 . The inclusionary criteria were organ transplantation/transplant (title, abstract) and China (institution/ affiliation). The exclusionary criteria were stem cells (title, abstract); mice (title, abstract); living donors (title, abstract); case reports/letters/editorials (document type). The searches were limited to English language and humans, and the years were 2000-date of search. The start date of 2000 was selected as this is when numbers of transplantations and associated research papers rapidly increased in China.

Medline, Scopus and Embase were searched on 5 April 2017 by WR, BB and RC-W. All relevant searches were downloaded into an EndNote library by WR. Duplicates were removed by EndNote filter. We did not identify further papers from other sources or search the references of included papers as we aimed to capture papers that are readily available through mainstream databases, and this was a scoping rather than systematic review. We recognised that our search strategy might potentially miss some papers published in difficult to find journals as well as those published in languages other than English, with a potential reduction in sensitivity. However, we do not think that papers omitted as a result of this strategy undermine the reliability of the findings. Rather, these omissions may make our estimate of the magnitude of any ethical breaches of publication standards conservative, based on the assumption that ethical compliance is likely to be higher in international journals published in English compared with journals published in China whether in Chinese or English language.

The title and abstracts remaining after removal of duplicates were screened for obvious exclusionary factors, with each author screening an equal number. All authors were trained in the use of the exclusionary criteria by screening the same 100 abstracts and titles. At the end of the pilot process, the exclusionary criteria were refined following discussion. The final exclusionary criteria for title and abstract screening were:

- transplants other than solid organs;

- transplants not occurring in mainland China;

- clinical case reports and/or incidental inclusion of data from Chinese transplant recipients;

- meta-analyses and systematic reviews;

- animal research;

- English-language journals published in China.

Articles which could not be eliminated by title and abstract were reviewed as full-text articles to determine eligibility. Prior to full-text review, five of the authors (WR, MPR, RC, BB, RC-W) undertook further training and benchmarking in use of the exclusionary criteria on full-text papers. This involved all five screening the same 20 papers, followed by discussion. The exclusionary criteria were finalised after this process (box 1), and four authors (RC, WR, MPR, BB) assessed full-text articles for eligibility.

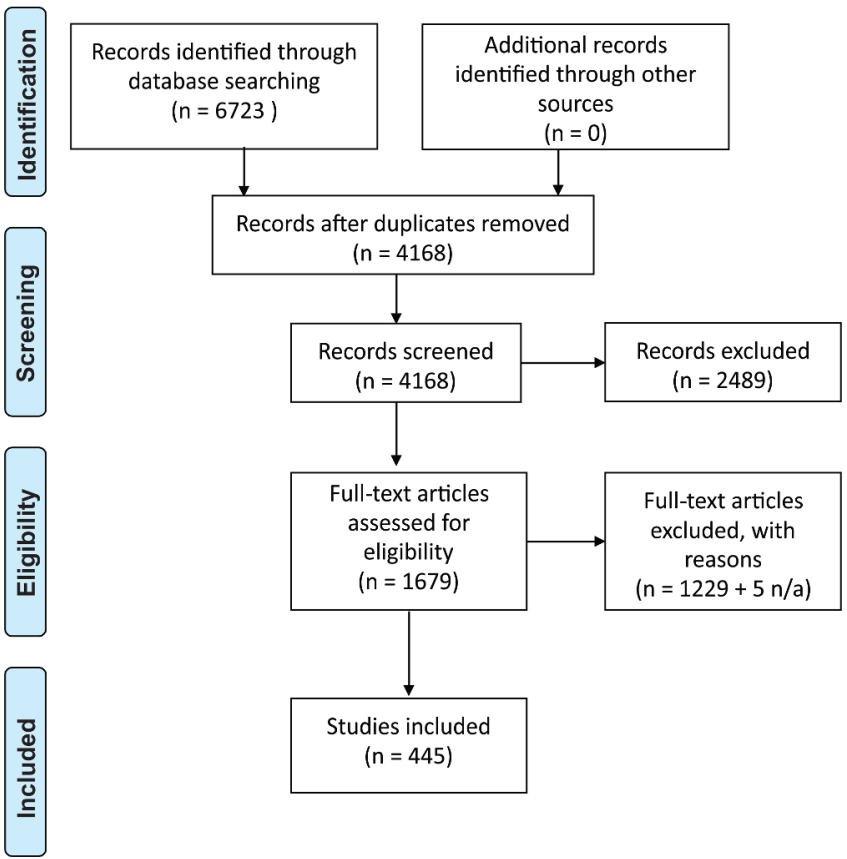

Figure 1 Preferred Reporting Items for Systematic Reviews and Meta-Analyses flow chart detailing search strategy. 
Table 2 Reasons for exclusions of full-text papers $(n=1229)$

\begin{tabular}{lc}
\hline Reason & Number \\
\hline Animal research & 12 \\
\hline Chinese journal & 96 \\
Case report & 3 \\
\hline Incidental inclusion & 14 \\
Kidneys & 637 \\
Living donors & 7 \\
\hline Not China & 380 \\
Not reviewed & 1 \\
\hline Other organs & 2 \\
\hline Other & 49 \\
Review paper & 28 \\
\hline
\end{tabular}

The reasons for exclusion were recorded, but where more than one reason was present, only the first reason noted by the data extractor was recorded. Papers reporting on recipients of kidney transplants were excluded at the full-text review stage after a trial of 200 full-text analyses. In this sample, $40 \%$ of kidney papers failed to report whether organ sources were living or deceased. As a key question in our research concerned procurement of organs from executed prisoners, we did not want to include a potentially large number of papers in which it was unclear whether or not organs were procured from living donors.

The same four authors who determined eligibility of full-text papers also extracted data from these papers onto pretested forms (see online supplementary file 2 for details extracted). Any details that could not be extracted

\begin{tabular}{|c|c|}
\hline Variable & Number (\%) \\
\hline Total number of included papers & $445(100)$ \\
\hline Total number of transplants reported & 85477 \\
\hline $\begin{array}{l}\text { Median number of transplants per } \\
\text { paper (range) }\end{array}$ & $72(1-20524)$ \\
\hline $\begin{array}{l}\text { Number of papers that explicitly stated } \\
\text { organs (hearts, livers, lungs) were from } \\
\text { deceased sources }\end{array}$ & $173(39)$ \\
\hline $\begin{array}{l}\text { Number of papers reporting research } \\
\text { ethics approval }\end{array}$ & $324(73)$ \\
\hline $\begin{array}{l}\text { Number of papers with any information } \\
\text { on the identity of the sources of organs }\end{array}$ & $63(14)$ \\
\hline $\begin{array}{l}\text { Number of papers with explicit } \\
\text { statement that no organs from } \\
\text { prisoners were used }\end{array}$ & $33(7)$ \\
\hline $\begin{array}{l}\text { Number of papers that reported } \\
\text { consent for donation }\end{array}$ & $6(1)$ \\
\hline $\begin{array}{l}\text { Number of papers with any statement } \\
\text { about the diagnosis of death in sources } \\
\text { (after brain death, after cardiac death) }\end{array}$ & $64(14)$ \\
\hline
\end{tabular}

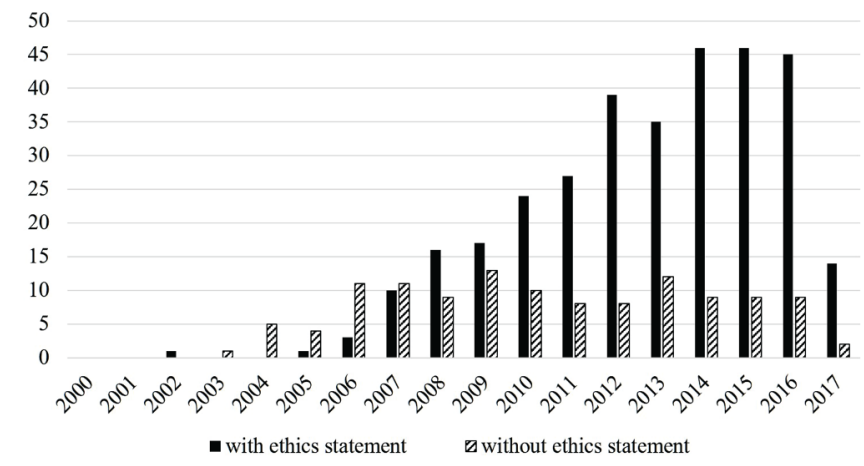

Figure 2 Articles per year with and without ethics statements.

with certainty were discussed by the group of authors to reach a consensus. No data extraction outcomes were unable to be resolved using this method. Data from $10 \%$ of included papers were checked by a second author.

This process is summarised in a Preferred Reporting Items for Systematic Reviews and Meta-Analyses diagram (figure 1).

\section{Patient and public involvement}

There was no patient or public involvement in this scoping review of published literature.

\section{RESULTS}

The searches identified 6723 records, leaving 4168 after duplicates were removed. After screening of abstracts and titles, 2489 records were excluded. One thousand six hundred seventy-nine full-text articles were screened for eligibility. One thousand two hundred twenty-nine were excluded (table 2). Four hundred forty-five papers were included in the final data set (see online supplementary file 3 ), and five papers were unavailable. ${ }^{25-29}$

The main results are summarised in table 3 . See online supplementary file 4 for a full table of results.

Overall, $324(73 \%)$ of the 445 papers included a statement regarding approval from an institutional or regional ethics committee. Most of these statements were of a general type such as: 'The study protocol was conducted in accordance with the standards of the Declaration of Helsinki and current ethical guidelines ${ }^{30}$; 'All protocols were approved by the ethics committee of the institution before the study began, and the protocols conformed to the ethical guidelines of the 1975 Helsinki Declaration' ${ }^{31}$ and 'The present study was approved by the ethics committee of Qingdao University (Qingdao, China)'. ${ }^{32}$ Few contained an IRB reference number or the date approval was granted. The majority of these statements reported that research participants (who were the transplant recipients) had given their informed consent.

The graph in figure 2 shows ethics approvals by year. These increased substantially after 2006, which was the year that TTS published its policy banning conference papers based on data from executed prisoners. ${ }^{7}$ 


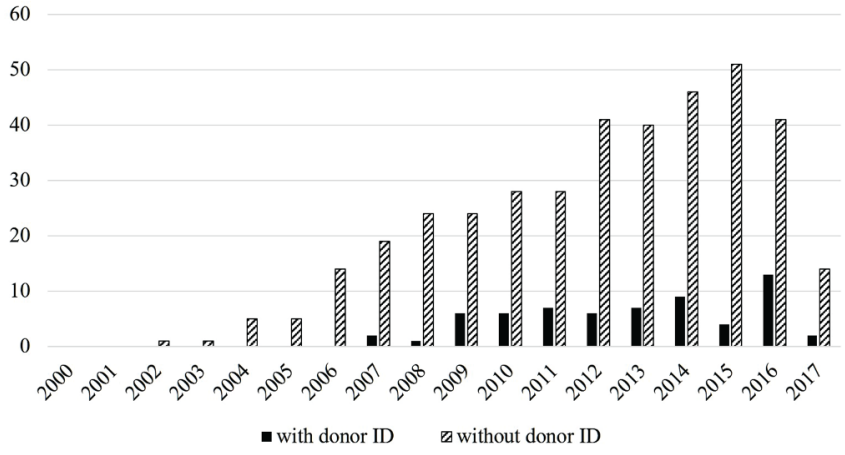

Figure 3 Articles per year with and without organ source ID.

Only 63 papers (14\%; see online supplementary file 5) included any information about the source of the organs (ie, whether or not the organs came from executed prisoners or volunteers, or if consent was given). This category of organ sources (donor identity) was interpreted inclusively. For example, papers reporting that sources gave informed consent were included here even if there was no explicit statement that the sources were not prisoners. Under Chinese policy, prisoners are permitted to make allegedly voluntary donations, which is in violation of TTS policy. ${ }^{33}$ The presence or absence of statements identifying organ sources by year is in figure 3. Only one paper published prior to 2007 included any information about identity of sources. ${ }^{34}$

Among the 63 papers that provided any information about the sources of organs, 33 (7.4\% of all included studies) stated explicitly that no organs from executed prisoners were used in the transplantations..$^{30} 31$ 34-65 Five of these also stated explicitly that organs were sourced from volunteers. ${ }^{35} 39464861$ Three of the 33 reported that informed consent was obtained from sources or their families, and these three papers also included a statement about ethics review. ${ }^{30} 4761$ That is, $<1 \%$ of included studies contain all three pieces of information mandated by TTS.

However, the claims that organs were not procured from prisoners cannot be true in many of these 33 papers. According to Chinese reports, there were only 120 voluntary donors in the whole of China up until to $2009,{ }^{16}$ and donation numbers were low during the nascent volunteer donor programme from 2010 to 2014 (table 4). ${ }^{66}$

Table 4 Numbers of volunteer organ donors in China 2000-2014

\begin{tabular}{lc}
\hline Year & $\begin{array}{l}\text { Number of volunteer donations } \\
\text { according to Chinese sources }\end{array}$ \\
\hline Up to 2009 & $120^{16}$ \\
2010 & $34^{66}$ \\
2011 & $132^{66}$ \\
2012 & $433^{66}$ \\
2013 & $849^{66}$ \\
2014 & $1702^{66}$ \\
\hline
\end{tabular}

Box 2 Text from papers reported in 'Other' category of donor ID information

All the donors were from traffic accidents or cerebral bleeding coma. $^{98}$

- No organ trafficking involved. ${ }^{99}$

- Organ donation was conducted legally, following local regulations. ${ }^{100}$

- Five donors were brain dead due to car accident, their respiration was maintained by mechanical ventilation and haemodynamics was stabilised by minimum doses of catecholamine. ${ }^{101}$

- The deceased donor livers were obtained through both social and legal donation. ${ }^{102}$

- The donation procedure followed the donation after cardiac death (DCD) guidelines of China. ${ }^{103}$

- Severe injuries and traffic accidents were the main reasons for DCD. ${ }^{104}$

- Normal control hearts came from autopsies or donors with no history of heart disease who died in accidents. ${ }^{105}$

- All the DBCD grafts were procured under controlled condition. Detailed information of the donation after brain and cardiac death (DBCD) donors was obtained from The Chinese Red Cross and the OPO records. ${ }^{106}$

- All donors were in hospital's intensive care unit before death (cause of death for each donor is supplied in a table). ${ }^{107}$

Yet 19 of the 33 papers claiming that organs were not procured from executed prisoners reported on 2688 transplants that took place prior to $2010 .^{3436-385354616367-77}$ One of these did not date the transplants but was published in 2010 reporting on grafts that had been stable for at least 2 years, indicating that the transplants had taken place prior to $2010 .^{37}$ Eight of the 33 papers report on 1212 transplants that occurred both before and after $2010^{3031} 353943525962$ and 6 of them report on 1556 transplants that took place during the period 2010-2014 during the pilot volunteer scheme. ${ }^{174255-576064}$

Turning to the 30 papers without explicit statement about prisoners, in 14 of these, statements indicated that organs were procured from volunteers, without specifying whether or not prisoners were excluded as volunteers. ${ }^{78-91}$ Three of the 14 stated that informed consent was provided by donors or their families. ${ }^{79} 8385$

Six papers reported that sources gave informed consent for donation, but did not record whether or not these were volunteers or prisoners. ${ }^{92-97}$

There were 10 papers that contained information implying that donations were from voluntary, non-prisoner sources, without explicitly stating this, or that consent was provided. ${ }^{98-107}$ The statements from these papers are in box 2.

These statements do not necessarily preclude inclusion of organs procured from executed prisoners. For example, two papers refer to legal donation, ${ }^{100} 102$ which might include organs from executed prisoners. Two papers refer to donors dying from severe injuries or in accidents. While these are potentially legitimate causes of death for organ donors, it is possible 
Table 5 Numbers of papers, including those with organ source identity statements by years and numbers of transplants

\begin{tabular}{|c|c|c|c|c|c|c|}
\hline & $\begin{array}{l}\text { No date of } \\
\text { transplants } \\
\text { in papers }\end{array}$ & $\begin{array}{l}\text { All transplants } \\
\text { prior to } 2010^{*}\end{array}$ & $\begin{array}{l}\text { Transplants } \\
\text { before and } \\
\text { after } 2010 \text { when } \\
\text { volunteer pilot } \\
\text { started }\end{array}$ & $\begin{array}{l}\text { All } \\
\text { transplants } \\
\text { took place } \\
\text { during pilot } \\
\text { 2010-2014 }\end{array}$ & $\begin{array}{l}\text { Transplants } \\
\text { occurred } \\
\text { before and } \\
\text { after } 2014\end{array}$ & $\begin{array}{l}\text { All } \\
\text { transplants } \\
\text { occurred } \\
\text { post-2014 }\end{array}$ \\
\hline Total included papers & 61 & 192 & 148 & 38 & 6 & 0 \\
\hline Total number of transplants & 2959 & 28442 & 49376 & 3937 & 763 & 0 \\
\hline $\begin{array}{l}33 \text { papers claiming no executed } \\
\text { prisoners } \\
\text { (no. of transplants) }\end{array}$ & & 19 (2688) & 8 (1212) & $6(1556)$ & 0 & 0 \\
\hline $\begin{array}{l}14 \text { papers claiming volunteers } \\
\text { (no. of transplants) }\end{array}$ & $1(321)$ & $8(2269)$ & $4(387)$ & $1(12)$ & 0 & 0 \\
\hline $\begin{array}{l}6 \text { papers claiming donors gave } \\
\text { consent (no. of transplants) }\end{array}$ & $1(40)$ & $3(200)$ & $2(1197)$ & 0 & 0 & 0 \\
\hline $\begin{array}{l}10 \text { papers with statement about } \\
\text { donors implying voluntariness or } \\
\text { consent (no. of transplants) }\end{array}$ & $2(11)$ & 0 & $4(619)$ & $4(153)$ & 0 & 0 \\
\hline
\end{tabular}

${ }^{*}$ In one paper, ${ }^{37}$ the dates of the transplants were not recorded, but the paper, published in 2010, reported on research subjects whose grafts had been stable for at least 2 years, indicating transplant prior to 2010.

that these could be extreme euphemisms for deaths caused by execution. 104105

Looking at all of the organ source ID statements by year of transplant, there are a total of 30 papers that either stated explicitly that no organs from prisoners were used (18) or indicated that organs were sourced voluntarily and/or with consent during the time period when executed prisoners were virtually the sole source (there were 120 volunteer donations across all of China in this period). These data are summarised in table 5, along with the same data for the whole set of included papers. Of the 445 papers, $192(43 \%)$ report on research that took place when the only organs available for transplant were from executed prisoners, while another 148 (33\%) spanned the start of the volunteer donor pilot so must include at least some data derived from executed prisoners.

The majority of the papers reporting on the identity of organ sources also reported some form of institutional ethics approval, but seven papers did not. ${ }^{37384479} 9496107$

Turning to the journals that published the 445 papers, a full list of these is in online supplementary file 6 .

Seventeen journals published five or more papers during the study period. In this subset of 17 , the proportion with ethics statements ranged from $38 \%$ to $100 \%$, while the proportion with identity statements regarding sources ranged from $0 \%$ to $40 \%$ (table 6 ).

Finally, in terms of journals with specific policies banning publication of research based on use of prisoners' organs, our study identifies one paper published in the American Journal of Transplantation ${ }^{89}$ and five papers published in Transplantation (the official journal of TTS) that appear to be in breach of their own stated policies. ${ }^{94}{ }^{108-111}$ One of these has over 300 citations. ${ }^{109}$

\section{DISCUSSION}

This study shows that the majority of the published literature identified in this scoping review reporting research on transplants in China from 2000 to April 2017 fails to comply with ethical standards regarding exclusion of research based on organs procured from prisoners. The body of literature contains a large number of papers that certainly, or almost certainly include data from executed prisoners given China's acknowledgement that during this period executed prisoners were the principal organ source. While TTS policy appears to have been partially successful in that the number of papers claiming IRB approvals rose steeply after that policy was published in 2006, the inclusion of this information has not addressed the major underlying concern about use of prisoners' organs. This is because the ethics review process focuses on the protection of research participants and their informed consent for participation in research. In transplant research, it is the recipients of transplants who are protected by IRB review, rather than the organ donors. Therefore, claims about compliance with the Declaration of Helsinki are largely irrelevant regarding the use of prisoners' organs in research. Few papers $(14 \%)$ include any information about the identity of organ sources. Only half of these explicitly state that no organs were procured from executed prisoners, but many of these claims are incompatible with what is known about volunteer organ sources in China.

Our findings raise significant issues. First, there is the broad question of what to do about the large body of literature based on research using organs from prisoners. It can be argued that prior to 2006, the international transplant community was not aware that in China at the time, all transplants were procured from executed prisoners. 
Table 6 List of journals publishing five or more papers, and numbers of those papers in which there were ethics and/or organ source identity statements

\begin{tabular}{|c|c|c|c|c|}
\hline Journal & CiteScore* & $\begin{array}{l}\text { Total papers } \\
\text { in journal out } \\
\text { of } 445(\%)\end{array}$ & $\begin{array}{l}\text { Number of papers } \\
\text { with ethics } \\
\text { statement (\%) }\end{array}$ & $\begin{array}{l}\text { Number of } \\
\text { papers with } \\
\text { donor ID (\%) }\end{array}$ \\
\hline Transplantation Proceedings & 0.98 & $65(15 \%)$ & $25(38 \%)$ & $12(18 \%)$ \\
\hline PLOS ONE & 3.11 & $20(4 \%)$ & 19 (95\%) & $5(25 \%)$ \\
\hline Clinical Transplantation & 1.67 & $16(4 \%)$ & $9(56 \%)$ & $3(19 \%)$ \\
\hline Liver Transplantation & 2.50 & $15(3 \%)$ & $12(80 \%)$ & $3(20 \%)$ \\
\hline Hepato-Gastroenterology & 0.98 & $14(3 \%)$ & $11(79 \%)$ & $2(14 \%)$ \\
\hline Experimental and Clinical Transplantation & 0.54 & $11(2 \%)$ & $10(91 \%)$ & $1(9 \%)$ \\
\hline Clinics and Research in Hepatology and Gastroenterology & 1.61 & $8(2 \%)$ & $7(88 \%)$ & $1(13 \%)$ \\
\hline International Journal of Clinical and Experimental Medicine & 1.17 & $8(2 \%)$ & $5(63 \%)$ & $1(13 \%)$ \\
\hline Annals of Transplantation & 1.29 & $7(2 \%)$ & $4(57 \%)$ & $0(0 \%)$ \\
\hline International Journal of Clinical Practice & 1.91 & $6(1 \%)$ & $5(83 \%)$ & $0(0 \%)$ \\
\hline Journal of Cancer Research and Clinical Oncology & 3.32 & $6(1 \%)$ & $5(83 \%)$ & $1(17 \%)$ \\
\hline Transplantation & 2.71 & $6(1 \%)$ & $5(83 \%)$ & $1(17 \%)$ \\
\hline European Journal of Gastroenterology and Hepatology & 1.88 & $5(1 \%)$ & $5(100 \%)$ & $1(20 \%)$ \\
\hline Experimental and Therapeutic Medicine & 1.42 & $5(1 \%)$ & $5(100 \%)$ & $1(20 \%)$ \\
\hline Medical Oncology & 1.91 & $5(1 \%)$ & $5(100 \%)$ & $0(0 \%)$ \\
\hline Medicine (United States) & 1.63 & $5(1 \%)$ & $5(100 \%)$ & $1(20 \%)$ \\
\hline Surgery (United States) & 2.77 & $5(1 \%)$ & $5(100 \%)$ & $2(40 \%)$ \\
\hline
\end{tabular}

*Average citations received per document published in the journal (source: Scopus).

However, post-2006 and the publication of TTS policy, professional claims of ignorance are hard to support. This lack of vigilance on the part of reviewers, editors and publishers is morally concerning, given the large numbers of papers (over 85\%) accepted for publication with no information at all on the source of organs, especially where individual journals have explicitly adopted relevant policy (Transplantation, American Journal of Transplantation).

Continued use of this research raises potential issues of complicity ${ }^{112}$ to the extent that the international community (including members of TTS, journal editors and peer-reviewers) condemn the use of executed prisoners' organs in research, but nonetheless benefit from this practice by allowing or facilitating the publication of such research, and subsequently using the findings. The obligations of third parties to avoid complicity depend in part on the magnitude of the moral wrong in question. ${ }^{113}$ Some research uses of datasets that were obtained illicitly may be permissible. ${ }^{114}$ By comparison, there is broad consensus that it is unethical to make use of the data obtained from Nazi and Japanese medical experiments where the victims were killed or harmed in the course of the research. ${ }^{115-117}$ The use of research based on organs sourced from executed Chinese prisoners, many of whom are prisoners of conscience, ${ }^{21118}$ falls at the severe end of this spectrum of moral wrongs in research. The obligation of third parties, such as peer-reviewers, publishers and editors to avoid complicity is therefore comparatively high in this case, warranting large-scale retractions and investigation of the 340 papers that are based exclusively or partially on data from executed prisoners (ie, all papers reporting on transplants that occurred prior to 2010 or spanning 2010: see table 5). In addition, due to lack of vigilance by the journals on reporting organ sources, readers risk witting or unwitting complicity to the extent that they use the published research findings. The continued presence of these papers in the literature creates moral hazard as it demonstrates that breaches of ethical standards in research will be ignored or tolerated, thereby removing incentives for future compliance with these standards.

Second, journal editors must decide how to handle published papers that use data from executed prisoners, and make almost certainly false claims about procuring organs from non-prisoner sources. In 29 of the 63 papers claiming or implying that organs were from non-prisoner sources and/or donated voluntarily or with consent, the claims are incompatible with what is known about voluntary donations across China in the relevant time period. There is less certainty regarding the falsity of claims in published papers reporting on transplants that took place between 2010 and 2014 given the existence of a pilot voluntary donation scheme. Determining the likely veracity of these claims requires sustained investigation, including of Chinese-language sources. Such investigation is possible, and has formed the basis for a retraction of a paper that falsely claimed more organs 
were procured from volunteers than there were reported volunteers at the relevant hospital. ${ }^{119-121}$ This is to date the only retraction in the literature. At the very least however, reviewers, editors and journals should be aware that prior to 2010 there were almost no voluntary donors, and that the alleged numbers of volunteer donors during the 2010-2014 pilot scheme were low (table 4). Given this situation, claims about volunteer sources for transplantation during these periods warrant scrutiny, with rejection of papers and author bans if adequate evidence of ethical organ sourcing is not provided.

Third, there is a pressing need for further reviews of the literature not included in this study. In particular, we need review of Chinese-language sources and English-language publications in China where a further large body of unethical research may be published, as well as review of papers published in languages other than English and Chinese. A future review of kidney transplant papers is also required, to fully document the extent of published unethical research.

Finally, there is a question regarding future publication of Chinese transplant papers. In our view, it is unacceptable to publish any papers that are highly likely to contain data derived from use of prisoners' organs. This includes data from transplants up until the end of 2014, given the difficulty of establishing organ provenance and the demonstrated lack of veracity in the claims of at least some authors. However, even transplants post-2015 may involve prisoners' organs. ${ }^{19}$ For this reason, we suggest an interim moratorium on publication of all relevant papers, pending an international summit to develop policy. A summit involving representatives from the International Committee of Medical Journal Editors, Committee on Publication Ethics, TTS and members of other relevant national and international transplant societies, together with China human rights experts, ethicists and any other relevant stakeholders could and should develop policy on handling future research. One outcome of this process could be the development of a checklist tool for all transplant papers, itemising mandatory information about organ sources. Given our lack of capacity in this study to report on papers involving kidney transplants due to missing information about the status of organ sources, one requirement of a checklist should be an unambiguous statement regarding whether organ sources were living or deceased. An international and widely adopted process of this kind would provide a strong incentive for China to move more rapidly towards an organ donation system that is ethical, transparent and verifiable. This incentive is currently lacking given the widespread publication of unethical research.

\section{LIMITATIONS}

The strengths of the study lie in its originality and robust methods. These give confidence that the results are reliable and likely to be conservative (given reasonable assumptions as described in the 'Methods' section) rather than to overestimate the findings. However, there are potential limitations. First, scoping reviews are less comprehensive than systematic reviews, making it possible that relevant papers were not identified and included. Second, we had to change our approach to data collection during the study, as the quality of data in the papers was often imprecise. This affected the study in two ways. We were not able to report on research involving kidney transplants due to lack of information as to whether sources were living or deceased; and we were not able to report on whether organs were obtained after death declared on cardiac or brain criteria as this information was inconsistently reported. Third, unless stated otherwise in the papers reporting on liver transplants, we have assumed the donors were deceased. It is possible that some of the transplants classified as deceased donor were from living split liver transplants, however we think the number is likely to be very low as deceased sourcing is the the most common type of transplant and numbers of living liver donations in China are low, at $7.37 \%$ of total cumulative liver transplants as of end 2011, according to official data. ${ }^{122}$ Fourth, we have reported on published literature, but during the period when only organs from executed prisoners were available, the pharmaceutical industry ran clinical trials on immunosuppressants for transplantation in China (including after 2007 when TTS policy was promulgated). ${ }^{123}$ Unpublished industry trials have not been included in our study. Finally, we have reported the total number of participants (and hence number of transplants) in the included studies, but this number is likely to be inflated by multiple publication of the same and overlapping research cohorts. However, as our aim was to report on whether or not published research met the ethical reporting standards mandated by TTS, we do not think this is a critical issue.

\section{CONCLUSION}

The transplant community has failed to implement ethical standards banning publication of research using material from executed prisoners. As a result, a large body of unethical published research now exists, raising questions of complicity to the extent that the transplant community uses and benefits from the results of this research. Our study has identified the extent of this problem as well as specific papers containing demonstrably false claims about organ sourcing. There has been a significant lack of vigilance and failure to adhere to accepted ethical standards by reviewers, editors and publishers. Researchers and clinicians who use this body of research risk complicity by implicitly accepting Chinese methods of organ procurement. We call for immediate retraction of all papers reporting research based on use of organs from executed prisoners, and an international summit to develop future policy for handling Chinese transplant research. 
Author affiliations

${ }^{1}$ Department of Clinical Medicine and Department of Philosophy, Macquarie University, Sydney, New South Wales, Australia

${ }^{2}$ Department of Philosophy, Macquarie University, Sydney, New South Wales, Australia

${ }^{3}$ Human Rights Law Foundation, New York, USA

${ }^{4}$ Department of Primary Health Care and General Practice, University of Otago, Wellington, New Zealand

${ }^{5}$ Australian Institute of Health Innovation, Macquarie University, Sydney, New South Wales, Australia

${ }^{6}$ No institutional affiliation, Sydney, Australia

${ }^{7}$ Australian Institute of Health Innovation, Macquarie University, Sydney, New South Wales, Australia

${ }^{8}$ Faculty of Health Sciences, University of Sydney, Sydney, New South Wales, Australia

Contributors All authors contributed substantially to the conception and design of the work and to the analysis and interpretation of the data. All authors contributed to revisions and approved the final draft. All authors agree to be accountable for all aspects of the work in ensuring that any questions related to the accuracy or integrity of any part of the work are appropriately investigated and resolved. Specific individual contributions in addition to the above: WR led the drafting of the paper and contributed to data extraction. MPR contributed to literature searching and data extraction. $\mathrm{AB}$ contributed to literature searching and drafting sections of the manuscript. $\mathrm{BB}$ contributed to data extraction and preparation of figures and tables. RC contributed to data extraction. RC-W contributed to resolving data extraction outcomes. MFS contributed to the Introduction. The lead author (WR, the manuscript's guarantor) affirms that the manuscript is an honest, accurate and transparent account of the study being reported. No important aspects of the study have been omitted; and that any discrepancies from the study as planned (and, if relevant, registered) have been explained.

Funding The authors have not declared a specific grant for this research from any funding agency in the public, commercial or not-for-profit sectors.

Competing interests $\mathrm{Dr} \mathrm{AB}$ is a member of the New Zealand Advocacy \& Initiatives Committee (NZAIC) of the International Coalition to End Transplant Abuse in China, Dr BB has nothing to disclose, Dr RC has nothing to disclose, Dr RC-W is a member of the Australian Advocacy and Initiatives Committee of the International Coalition to End Transplant Abuse in China, Professor MFS is a member of the Ethics Committee of Doctors Against Forced Organ Harvesting, and a member of the Australian Advocacy and Initiatives Committee of the International Coalition to End Transplant Abuse in China, MPR reports that he is an occasional expert contributor to the International Coalition to End Transplant Abuse in China, Professor WR is a Director of the NGO 'International Coalition to End Transplant Abuse in China' and is chair of its International Advisory Committee.

Patient consent for publication Not required.

Provenance and peer review Not commissioned; externally peer reviewed.

Data sharing statement The full list of 445 included studies is published in online supplementary file 3 .

Open access This is an open access article distributed in accordance with the Creative Commons Attribution Non Commercial (CC BY-NC 4.0) license, which permits others to distribute, remix, adapt, build upon this work non-commercially, and license their derivative works on different terms, provided the original work is properly cited, appropriate credit is given, any changes made indicated, and the use is non-commercial. See: http://creativecommons.org/licenses/by-nc/4.0/.

\section{REFERENCES}

1. World Health Organization. WHO guiding principles on human cell, tissue and organ transplantation. Transplantation 2010;90:229-33.

2. WMA - The World Medical Association. WMA Statement on organ and tissue donation. https://www.wma.net/policies-post/wmastatement-on-organ-and-tissue-donation/ (Accessed 7 Feb 2018).

3. Stock P. Policy and Ethics. The Transplantation Society. https:// www.tts.org/about-tts-5/governance/policy-a-ethics (Accessed 7 Feb 2018).

4. Amnesty International Publications. Amnesty International Report 2011: the State of the World's Human Rights: Amnesty International Publications, 2011.
5. The Declaration of Istanbul Custodian Group. The declaration of istanbul on organ trafficking and transplant tourism. http://www. declarationofistanbul.org/ (Accessed 7 Feb 2018).

6. Tibell A. The Transplantation Society's policy on interactions with China. Transplantation 2007;84:292-4.

7. The Transplantation Society. The Transplantation Society's principles for interacting with China. 2006. https://www.tts.org/ index.php?option=com_content\&view=article\&id=11\&ltemid=223 (Accessed 28 Sep 2018).

8. Caplan AL, Danovitch G, Shapiro M, et al. Time for a boycott of Chinese science and medicine pertaining to organ transplantation. Lancet 2011;378:1218.

9. Lavee J, West LJ. A call for a policy change regarding publications based on transplantation of organs from executed prisoners. $J$ Heart Lung Transplant 2012;31:555-6.

10. Danovitch GM, Shapiro ME, Lavee J. The use of executed prisoners as a source of organ transplants in China must stop. Am J Transplant 2011;11:426-8.

11. Caplan AL, Rockman HA, Turka LA. Editorial position on publishing articles on human organ transplantation. J Clin Invest 2012;122.2.

12. Smith CS. The New York Times. Doctor says he took transplant organs from executed Chinese Prisoners. 2001. https://www. nytimes.com/2001/06/29/world/doctor-says-he-took-transplantorgans-from-executed-chinese-prisoners.html (Accessed 17 Feb 2018).

13. Huang J. Ethical and legislative perspectives on liver transplantation in the People's Republic of China. Liver Transp/ 2007;13:193-6.

14. BBC News. China admits death row organ use: BBC, 2018.

15. Wang $\mathrm{H}$. New era for organ donation and transplant in China. Interview by Fiona Fleck. Bull World Health Organ 2012;90:802-3.

16. Zhao H, Wu N. 专访黄洁夫|中国器官移植事业光明正大地登上世界舞 台 [Exclusive Interview with Huang Jiefu: the China organ transplant field justly and honorably steps onto the world stage]. China Healthcare. 2015. https://perma.cc/X73M-HNRX (Accessed 23 Mar 2018).

17. Huang JF, Zheng SS, Liu YF, et al. China organ donation and transplantation update: the Hangzhou Resolution. Hepatobiliary Pancreat Dis Int 2014;13:122-4.

18. Paul NW, Caplan A, Shapiro ME, et al. Human rights violations in organ procurement practice in China. BMC Med Ethics 2017;18:11.

19. Kirchgaessner S. The Guardian. China may still be using executed prisoners' organs, official admits. 2017. http://www.theguardian com/world/2017/feb/07/china-still-using-executed-prisonersorgans-transplants-vatican (Accessed 21 Mar 2018).

20. Caplan $A$. The use of prisoners as sources of organs-an ethically dubious practice. Am J Bioeth 2011;11:1-5.

21. Matas D, Kilgour D. Bloody Harvest: the killing of Falun Gong for their organs. Woodstock, ON: Seraphim Editions, 2009.

22. United States. Congressional-Executive Commission on China. Falun Gong in China: review and update: hearing before the congressional-executive commission on China, One Hundred Twelfth Congress, Second Session: U.S. Government Printing Office, 2012.

23. Levac D, Colquhoun H, O'Brien KK. Scoping studies: advancing the methodology. Implement Sci 2010;5:69.

24. Arksey H, O'Malley L. Scoping studies: towards a methodologica framework. Int J Soc Res Methodol 2005;8:19-32.

25. Xie W, Ye Q, Wan $Q$. A comparison of risk factors for septic shock in renal transplant recipients with liver transplant recipients with bloodstream infections. Exp Clin Cardiol 2014;20:3587-97.

26. Ye $Q, M a Y$, Wan $Q$, et al. The distribution and resistance of pathogens causing blood stream infections following liver transplantation: a clinical analysis of 69 patients. Hepatogastroenterology 2014;61:2311-4.

27. Zhu L, Liao S, Wang N, et al. Dose regimens for Chinese adult liver transplant recipients according to the genetic polymorphisms of CYP2C9, CYP2C19, and CYP3A5 in recipients and donors. Int $J$ Clin Pharmacol Ther 2016;54:587-96.

28. Nie $X$, Wan $Q, Y e ~ Q$, et al. Fungemias following liver or kidney transplantation: A clinical analysis of 17 patients. J Pure Appl Microbiol 2014;8:667-70.

29. Tsai HI, Tsai YF, Hp Y. Arterial waveform monitoring during liver transplantation. Exp Clin Cardiol 2014;20:145-57.

30. Yang X, Lu Q, Tang T, et al. Prediction of the prognosis after liver transplantation in severe hepatitis B-induced liver failure and clinical decision for liver transplantation. J Surg Res 2013;183:846-51.

31. Mu HJ, Xie P, Chen JY, et al. Association of TNF- $\alpha$, TGF- $\beta 1$, IL-10, IL-6, and IFN- $\gamma$ gene polymorphism with acute rejection and infection in lung transplant recipients. Clin Transplant 2014:28:1016-24. 
32. Hu WY, Wu LQ, Su Z, et al. Expression of human leukocyte antigen-G and acute rejection in patients following liver transplantation. Exp Ther Med 2014;8:1291-5.

33. Beijing Times. 黄洁夫 : 内地已有38家医院停用死囚器官[Huang Jiefu: 38 Hospitals in China have already stopped using organs from prisoners]. 2014. http://npc.people.com.cn/n/2014/0307/ c376899-24566378.html (Accessed 23 Mar 2018).

34. Guo CB, Li YC, Zhang MM, et al. Early postoperative care of liver transplantation for infants with biliary atresia during pediatric intensive care unit stay. Transplant Proc 2010;42:1750-4.

35. Lei J, Yan L. Outcome comparisons among the Hangzhou, Chengdu, and UCSF criteria for hepatocellular carcinoma liver transplantation after successful downstaging therapies. $J$ Gastrointest Surg 2013;17:1116-22.

36. Chen YB, Li SD, Ju BL, et al. Suitable calcineurin inhibitor concentrations for liver transplant recipients in the Chinese population. Transplant Proc 2011;43:1751-3.

37. Chu Z, Zhang J, Zhao Y, et al. Influence of immunosuppressive drugs on the development of CD4(+)CD25(high) Foxp3(+) T cells in liver transplant recipients. Transplant Proc 2010;42:2599-601.

38. Gu L, Yu YC, Yc Y. Clinical outcome of dental implants placed in liver transplant recipients after 3 years: a case series. Transplant Proc 2011;43:2678-82.

39. Lei JY, Wang WT, Yan LN. Hangzhou criteria for liver transplantation in hepatocellular carcinoma: a single-center experience. Eur J Gastroenterol Hepatol 2014;26:200-4.

40. Li J, Liu B, Yan LN, et al. Reversal of graft steatosis after liver transplantation: prospective study. Transplant Proc 2009;41:3560-3.

41. Ling $\mathrm{Q}$, Xie $\mathrm{H}, \mathrm{Lu} \mathrm{D}$, et al. Association between donor and recipient TCF7L2 gene polymorphisms and the risk of new-onset diabetes mellitus after liver transplantation in a Han Chinese population. $J$ Hepatol 2013;58:271-7.

42. Ling $\mathrm{Q}, \mathrm{Xu} \mathrm{X}$, Wang $\mathrm{K}$, et al. Donor PPAR $\alpha$ gene polymorphisms influence the susceptibility to glucose and lipid disorders in liver transplant recipients: a strobe-compliant observational study. Medicine 2015;94:e1421.

43. Lu D, Xu X, Wang J, et al. The influence of a contemporaneous portal and hepatic artery revascularization protocol on biliary complications after liver transplantation. Surgery 2014;155:190-5.

44. Pan C, Shi Y, Zhang JJ, et al. Single-center experience of 253 porta vein thrombosis patients undergoing liver transplantation in China. Transplant Proc 2009;41:3761-5.

45. Wang SY, Tang HM, Chen GQ, et al. Effect of ursodeoxycholic acid administration after liver transplantation on serum liver tests and biliary complications: a randomized clinical trial. Digestion 2012;86:208-17.

46. Wang Y, Liu Y, Han R, et al. Monitoring of CD95 and CD38 expression in peripheral blood T lymphocytes during active human cytomegalovirus infection after orthotopic liver transplantation. J Gastroenterol Hepatol 2010;25:138-42

47. Xiao L, Fu ZR, Ding GS, et al. Prediction of survival after liver transplantation for chronic severe hepatitis $B$ based on preoperative prognostic scores: a single center's experience in China. World $J$ Surg 2009;33:2420-6.

48. Xu J, Shen ZY, Chen XG, et al. A randomized controlled trial of Licartin for preventing hepatoma recurrence after liver transplantation. Hepatology 2007;45:269-76.

49. Xu X, Guo HJ, Xie HY, et al. ZIP4, a novel determinant of tumor invasion in hepatocellular carcinoma, contributes to tumor recurrence after liver transplantation. Int J Biol Sci 2014;10:245-56.

50. Xu X, Liu X, Ling Q, et al. Artificial liver support system combined with liver transplantation in the treatment of patients with acute-onchronic liver failure. PLoS One 2013;8:e58738.

51. Xu X, Tu Z, Wang B, et al. A novel model for evaluating the risk of hepatitis B recurrence after liver transplantation. Liver Int 2011;31:1477-84.

52. Xue F, Higgs BW, Huang J, et al. HERC5 is a prognostic biomarker for post-liver transplant recurrent human hepatocellular carcinoma. J Transl Med 2015;13:379.

53. Zhu M, Li Y, Xia Q, et al. Strong impact of acute kidney injury on survival after liver transplantation. Transplant Proc 2010;42:3634-8.

54. Chen J, Wang Y, Shen Z, et al. Early diagnostic value of plasma PCT and BG assay for CRBSI after OLT. Transplant Proc 2011;43:1777-9.

55. Fan X, Chen Z, Nasralla D, et al. The organ preservation and enhancement of donation success ratio effect of extracorporeal membrane oxygenation in circulatory unstable brain death donor. Clin Transplant 2016;30:1306-13.

56. Ling Q, Xie H, Li J, et al. Donor graft micrornas: a newly identified player in the development of new-onset diabetes after liver transplantation. Am J Transplant 2017;17:255-64.
57. Liu C, Tsai H-L, Chin T, et al. Experience of surgical treatment for hepatoblastoma. Formosan Journal of Surgery 2016;49:56-62.

58. Wang Y, Shen Z, Zhu Z, et al. Clinical values of AFP, GPC3 mRNA in peripheral blood for prediction of hepatocellular carcinoma recurrence following OLT: AFP, GPC3 mRNA for prediction of HCC. Hepat Mon 2011;11:195-9.

59. Xu X, Ling Q, Wang J, et al. Donor miR-196a-2 polymorphism is associated with hepatocellular carcinoma recurrence after liver transplantation in a Han Chinese population. Int J Cancer 2016;138:620-9.

60. Yu Z, Sun Z, Yu S, et al. Safety limitations of fatty liver transplantation can be extended to $40 \%$ : experience of a single centre in China. Liver Int 2016.

61. Zhang M, Yin F, Chen B, et al. Pretransplant prediction of posttransplant survival for liver recipients with benign end-stage liver diseases: a nonlinear model. PLoS One 2012;7:e31256.

62. Zhong L, Li H, Li Z, et al. C7 genotype of the donor may predict early bacterial infection after liver transplantation. Sci Rep 2016;6:24121

63. Jiang L, Lei JY, Wang WT, et al. Immediate radical therapy or conservative treatments when meeting the Milan criteria for advanced HCC patients after successful TACE. J Gastrointest Surg 2014;18:1125-30.

64. Yu S, Yu J, Zhang W, et al. Safe use of liver grafts from hepatitis B surface antigen positive donors in liver transplantation. $J$ Hepatol 2014;61:809-15

65. Lee WC, Lee CS, Wang YC, et al. Validation of the model for endstage liver disease score criteria in urgent liver transplantation for acute flare up of Hepatitis B. Medicine 2016;95:e3609.

66. China Organ Transplantation Development Foundation. 中国模 式+广州贡献'获国际器官捐献与移植学界点赞 ['China model + Guangzhou donations' are praised by international organ donation and transplantation community]. 2017. http://news.dayoo.com/ guangzhou/201712/16/139995_51994682.htm (Accessed 30 Mar 2018).

67. Li MR, Chen GH, Cai CJ, et al. High hepatitis B virus DNA level in serum before liver transplantation increases the risk of hepatocellular carcinoma recurrence. Digestion 2011;84:134-41.

68. Ling $\mathrm{Q}, \mathrm{Xu} \mathrm{X}, \mathrm{Li} \mathrm{J}$, et al. A new serum cystatin C-based equation for assessing glomerular filtration rate in liver transplantation. Clin Chem Lab Med 2008;46:405-10.

69. Pan C, Wang C, Pan W, et al. Usefulness of real-time threedimensional echocardiography to quantify global left ventricular function and mechanical dyssynchrony after heart transplantation. Acta Cardiol 2011;66:365-70.

70. Wang W, Ye Y, Wang T, et al. Prognostic prediction of male recipients selected for liver transplantation: With special attention to neutrophil to lymphocyte ratio. Hepatol Res 2016;46:899-907.

71. Wang Y, Liu Y, Han R, et al. Temporal evolution of soluble Fas and Fas ligand in patients with orthotopic liver transplantation. Cytokine 2008;41:240-3.

72. Xiao M, Xu X, Zhu H, et al. Efficacy and safety of basiliximab in liver transplantation for patients with hepatitis $B$ virus-related diseases: a single centre study. Int J Clin Pract 2015;69:35-42.

73. Xu L, Li X, Xu M, et al. Perioperative use of ECMO during double lung transplantation. Asaio J 2009;55:255-8.

74. Xu X, Ke QH, Shao ZX, et al. The value of serum alpha-fetoprotein in predicting tumor recurrence after liver transplantation for hepatocellular carcinoma. Dig Dis Sci 2009;54:385-8.

75. Xu X, Qu K, Wan Y, et al. Tumor existence and tumor size as prognostic factors in hepatitis $B$ virus-related cirrhosis patients who underwent liver transplantation. Transplant Proc 2014;46:1389-92.

76. Xu ZD, Xu HT, Li WW, et al. Influence of preoperative diastolic dysfunction on hemodynamics and outcomes of patients undergoing orthotopic liver transplantation. Int J Clin Exp Med 2013;6:351-7.

77. Wang $Y$, Zhang M, Liu ZW, et al. The ratio of circulating regulatory $T$ cells (Tregs)/Th17 cells is associated with acute allograft rejection in liver transplantation. PLoS One 2014;9:e112135.

78. Chen ZY, Yan LN, Zeng Y, et al. Preliminary experience with indications for liver transplantation for hepatolithiasis. Transplant Proc 2008;40:3517-22.

79. Fan J, Yang GS, Fu ZR, et al. Liver transplantation outcomes in 1,078 hepatocellular carcinoma patients: a multi-center experience in Shanghai, China. J Cancer Res Clin Oncol 2009;135:1403-12.

80. Gao $\mathrm{Y}$, Zhang M, Li J, et al. Circulating FoxP3+ regulatory $\mathrm{t}$ and interleukin17-producing th17 cells actively influence hbv clearance in de novo hepatitis b virus infected patients after orthotopic liver transplantation. PLoS One 2015;10:e0137881. 
81. Hu XX, Yan LN. Retrospective analysis of prognostic factors after liver transplantation for intrahepatic cholangiocarcinoma in China: a single-center experience. Hepatogastroenterology 2011;58:1255-9.

82. Li F, Yang M, Li B, et al. Initial clinical results of orthotopic liver transplantation for hepatic alveolar echinococcosis. Liver Transpl 2007;13:924-6.

83. Li H, He JW, Fu BS, et al. Immunosuppressant-related hip pain after orthotopic liver transplant. Exp Clin Transplant 2013;11:32-8.

84. Zhang D, Jiao Z, Han J, et al. Clinicopathological features of hepatitis $B$ virus recurrence after liver transplantation: eleven-year experience. Int J Clin Exp Pathol 2014;7:4057-66.

85. Zhang M, Yin F, Chen B, et al. Mortality risk after liver transplantation in hepatocellular carcinoma recipients: a nonlinear predictive model. Surgery 2012;151:889-97.

86. Zhang Y, Yan L, Wen T, et al. Prophylaxis against hepatitis B virus recurrence after liver transplantation for hepatitis $B$ virusrelated end-stage liver diseases with severe hypersplenism and splenomegaly: role of splenectomy. J Surg Res 2012;178:478-86.

87. Lei JY, Yan LN, Wang WT, et al. Health-related quality of life and psychological distress in patients with early-stage hepatocellular carcinoma after hepatic resection or transplantation. Transplant Proc 2016;48:2107-11.

88. Lin B, Geng L, Zheng Z, et al. The predictive value of blood neutrophil-lymphocyte ratio in patients with end-stage liver cirrhosis following ABO-incompatible liver transplantation. J Res Med Sci 2016;21:20-5.

89. Jiang L, Yan L, Li B, et al. Prophylaxis against hepatitis B recurrence posttransplantation using lamivudine and individualized low-dose hepatitis B immunoglobulin. Am J Transplant 2010;10:1861-9.

90. Chen Z, Gong R, Luo Y, et al. Surgical procedures for hepatolithiasis. Hepatogastroenterology 2010;57:134-7.

91. Lin $\mathrm{XH}$, Teng $\mathrm{S}$, Wang $\mathrm{L}$, et al. Fatigue and its associated factors in liver transplant recipients in Beijing: a cross-sectional study. BMJ Open 2017;7:e011840.

92. Ran JH, Zhang SN, Liu J, et al. In-hospital and follow-up outcomes of patients undergoing orthotopic liver transplantation after hepatic artery reconstruction with an iliac interposition graft. Int J Clin Exp Med 2016;9:3939-45.

93. Xu X, Ling Q, Gao F, et al. Hepatoprotective effects of marine and kuhuang in liver transplant recipients. Am J Chin Med 2009;37:27-34.

94. Xu X, Ling Q, Zhang M, et al. Outcome of patients with hepatorenal syndrome type 1 after liver transplantation: Hangzhou experience. Transplantation 2009;87:1514-9.

95. Zhu XS, Wang SS, Cheng Q, et al. Using ultrasonography to monitor liver blood flow for liver transplant from donors supported on extracorporeal membrane oxygenation. Liver Transpl 2016;22:188-91.

96. Yuefeng $\mathrm{M}$, Weili F, Wenxiang $\mathrm{T}$, et al. Long-term outcome of patients with lamivudine after early cessation of hepatitis $B$ immunoglobulin for prevention of recurrent hepatitis B following liver transplantation. Clin Transplant 2011;25:517-22.

97. Liu YY, Li CP, Huai MS, et al. Comprehensive comparison of three different immunosuppressive regimens for liver transplant patients with hepatocellular carcinoma: steroid-free immunosuppression, induction immunosuppression and standard immunosuppression. PLoS One 2015;10.

98. Chen $\mathrm{Y}$, Zhang $\mathrm{H}$, Xiao $\mathrm{X}$, et al. Peripheral blood transcriptome sequencing reveals rejection-relevant genes in long-term heart transplantation. Int J Cardiol 2013;168:2726-33.

99. Gao Y, Ren H, Meng F, et al. Pathological roles of interleukin-22 in the development of recurrent hepatitis $\mathrm{C}$ after liver transplantation. PLoS One 2016;11:e0154419.

100. Gao YJ, Zhang M, Jin B, et al. Clinical-pathological analysis of hepatitis $B$ virus recurrence after liver transplantation in Chinese patients. J Gastroenterol Hepatol 2014;29:554-60.

101. Li H, Li J, Wang Y, et al. Proteomic analysis of effluents from perfused human heart for transplantation: identification of potential biomarkers for ischemic heart damage. Proteome Sci 2012;10:21.
102. Li WX, Li Z, Gao PJ, et al. Histological differentiation predicts postliver transplantation survival time. Clin Res Hepatol Gastroenterol 2014;38:201-8.

103. Sun $X Y$, Dong JH, Qin KE, et al. Single-center study on transplantation of livers donated after cardiac death: A report of 6 cases. Exp Ther Med 2016;11:988-92.

104. Zhu XS, Gao YH, Wang SS, et al. Contrast-enhanced ultrasound diagnosis of splenic artery steal syndrome after orthotopic liver transplantation. Liver Transp/ 2012;18:966-71.

105. Liu S, Bai Y, Huang J, et al. Do mitochondria contribute to left ventricular non-compaction cardiomyopathy? New findings from myocardium of patients with left ventricular non-compaction cardiomyopathy. Mol Genet Metab 2013;109:100-6.

106. Liu X, Wang B, Zhang X, et al. Liver transplantation using donation after brain and cardiac death: a single-center experience in China. Transplant Proc 2016;48:1879-86.

107. Yuan X, Chen C, Zhou J, et al. Organ donation and transplantation from donors with systemic infection: a single-center experience. Transplant Proc 2016;48:2454-7.

108. Liang TB, Li DL, Liang L, et al. Intraoperative blood salvage during liver transplantation in patients with hepatocellular carcinoma: efficiency of leukocyte depletion filters in the removal of tumor cells. Transplantation 2008;85:863-9.

109. Zheng SS, Xu X, Wu J, et al. Liver transplantation for hepatocellular carcinoma: Hangzhou experiences. Transplantation 2008:85:1726-32.

110. Xie SB, Zhu JY, Ying Z, et al. Prevention and risk factors of the HBV recurrence after orthotopic liver transplantation: 160 cases followup study. Transplantation 2010;90:786-90.

111. Xue F, Zhang J, Han L, et al. Immune cell functional assay in monitoring of adult liver transplantation recipients with infection. Transplantation 2010;89:620-6.

112. Cohen G. Casting the first stone: who can, and who can't, condemn the terrorists? Royal Institute of Philosophy Supplement 2006;58:113-36.

113. Hickey D, Li SS, Morrison C, et al. Unit 731 and moral repair. J Med Ethics 2017:43:270-6.

114. Thomas DR, Pastrana S, Hutchings $A$, et al. Ethical issues in research using datasets of illicit origin. In: Proceedings of the 2017 Internet Measurement Conference: ACM, 2017:445-62.

115. Green RM. Benefiting from 'evil': an incipient moral problem in human stem cell research. Bioethics 2002;16:544-56.

116. ABC News. Is it Ethical to Use Data from Nazi Medical Experiments?. 2015. http://www.abc.net.au/religion/articles/2015/ 06/11/4253136.htm (Accessed 30 Mar 2018).

117. Bärnighausen T. Barbaric Research, Japanese Human Experiments in Occupied China: Relevance, Alternatives, Ethics. Eckart WU, ed. Man, medicine, and the state: the human body as an object of government sponsored medical research in the 20th Century: Steiner, 2006.

118. Gutmann E. The slaughter: mass killings, organ harvesting, and China's secret solution to its dissident problem: Prometheus Books Amherst, 2014

119. Retraction: "Safety limitations of fatty liver transplantation can be extended to $40 \%$ : experience of a single centre in China", by Yu Z., Yu S., Zhang L., Feng X., Zhang M., et al. Liver Int 2017;37:767.

120. Rogers WA, Fiatarone Singh MA, Lavee J. Papers based on data concerning organs from executed prisoners should not be published. Liver Int 2017;37:769.

121. Rogers WA, Fiatarone Singh MA, Lavee J. Papers based on data concerning organs from executed prisoners should not be published: Response to Zheng and Yan. Liver Int 2017;37:771-2.

122. Jiang WS, Zhou ZY. China Liver Transplant Registry Annual Report 2011. China Liver Transplant Registry. 2011.

123. Schwarz A. Responsibilities of international pharmaceutical companies in the abusive Chinese organ transplant system. In: Matas D, Trey T, eds. State organs: transplant abuse in China. Woodstock, Ontario: Seraphim Publishers, 2012:119-35. 